\title{
A molecular boron cluster-based chromophore with dual emission
}

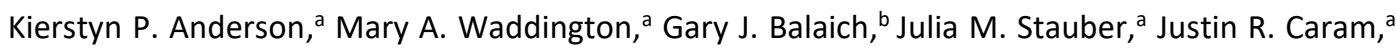
Peter I. Djurovich, ${ }^{\mathrm{C}}$ and Alexander M. Spokoyny *a

\begin{abstract}
Bromination of the luminescent borane, anti- $\mathrm{B}_{18} \mathrm{H}_{22}$, via electrophilic substitution using $\mathrm{AlCl}_{3}$ and $\mathrm{Br}_{2}$ yields the monosubstituted derivative $4-\mathrm{Br}$-anti- $\mathrm{B}_{18} \mathrm{H}_{21}$ as an air-stable crystalline solid. In contrast to the unsubstituted parent compound, 4- $\mathrm{Br}$-anti- $\mathrm{B}_{18} \mathrm{H}_{21}$ product possesses dual emission upon excitation with UV light and exhibits fluorescence at $410 \mathrm{~nm}$ and phosphorescence at $503 \mathrm{~nm}$, with $\Phi_{\text {total }}=0.07$ in oxygen-free cyclohexane. Increased oxygen content in cyclohexane solution quenches the phosphorescence signal. The fluorescent signal intensity remains unaffected by oxygen, suggesting that this molecule could be used as a ratiometric oxygen probe.
\end{abstract}

\section{Introduction}

Boron-containing luminescent molecules have been widely known and researched over decades for a variety of applications, including intracellular imaging, ${ }^{1}$ sensors, ${ }^{2}$ organic light emitting diodes $^{3}$ photovoltaics, ${ }^{4}$ and lasers. ${ }^{5}$ While the properties of molecules such as triarylboranes and borate-based dyes have received considerable attention, research into luminescent boron-rich hydride-based materials remains an underexplored field in which closodicarbadodecaboranes, also known as carboranes, have remained a central focus. This research has successfully developed emissive materials that incorporate carboranyl groups as components in metal complexes or luminescent polymers. ${ }^{3,6}$ However, due to the large band gap of carboranes $(\sim 8 \mathrm{eV})$, substitution onto the icosahedral cage is usually required for the molecule to participate in visible light transitions. ${ }^{7}$ Consequently, a significant amount of work has focused on carborane functionalization methods. ${ }^{8}$ In fact, only one known polyhedral borane to date, anti- $\mathrm{B}_{18} \mathrm{H}_{22}$, possesses inherent luminescence. This unique cluster best resembles two nido- $\mathrm{B}_{10} \mathrm{H}_{14}$ molecules fused at two vertices, forming an 18 -vertex borane (Figure 1). While two isomers of $\mathrm{B}_{18} \mathrm{H}_{22}$ are known- anti$\mathrm{B}_{18} \mathrm{H}_{22}$ and syn- $\mathrm{B}_{18} \mathrm{H}_{22^{-}}$only the former is luminescent, featuring intense blue fluorescence at $407 \mathrm{~nm}$ when irradiated at $340 \mathrm{~nm}$ that is accompanied by a high quantum yield of $0.97 .{ }^{9}$ Following its discovery in $1962,{ }^{10}$ detailed analyses of its luminescence have been described, ${ }^{9,11}$ which found that both the HOMO and LUMO are distributed evenly across the boron cage. The absorbed energy in

a. Department of Chemistry and Biochemistry and California NanoSystems Institute (CNSI), University of California, Los Angeles, California 90095, United States

b. Department of Chemistry and Chemistry Research Center, United States Air Force

Academy, Colorado Springs, Colorado 80840, United States

- Department of Chemistry, University of Southern California, Los Angeles,

California 90089, United States

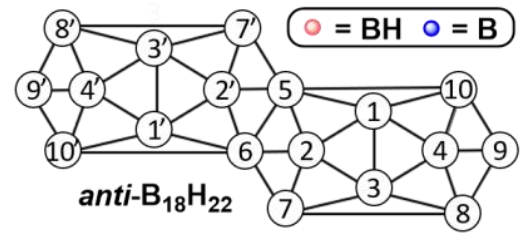

This work

Related Derivatives of anti- $\mathrm{B}_{18} \mathrm{H}_{22}$

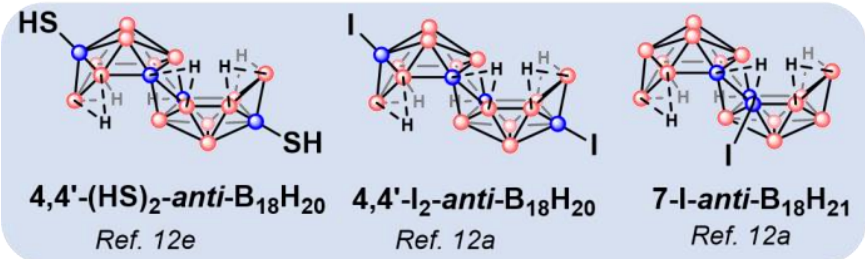

Figure 1: Top) Two-dimensional projection of anti- $\mathrm{B}_{18} \mathrm{H}_{22}$ and the brominated derivative discussed in this work. Bottom) Representations of select previously reported derivatives of anti- $\mathrm{B}_{18} \mathrm{H}_{22}$.

the $S_{1}$ state is redistributed across multiple bonds resulting in a prolonged $S_{1}$ lifetime and, consequently, fluorescence. ${ }^{9}, 11$ Since then, however, only a handful of synthetic derivatives of anti- $\mathrm{B}_{18} \mathrm{H}_{22}$ have been reported (Figure 1),12 and a comprehensive synthetic foundation for this fascinating boron cluster system has yet to be established. From the existing reports it is clear that functionalization of the cluster dramatically alters its emissive properties. ${ }^{10}$ For example, thiolation of the cluster gives $4,4^{\prime}-(\mathrm{HS})_{2}-$ anti- $\mathrm{B}_{18} \mathrm{H}_{20}$, which displays red-shifted luminescence with fluorescent emission at $536 \mathrm{~nm}$ and phosphorescent emission at $597 \mathrm{~nm}^{12 \mathrm{e}}$ Reaction with pyridine yields a rearranged boron cage derivative, $\mathrm{B}_{18} \mathrm{H}_{20}\left(\mathrm{NC}_{5} \mathrm{H}_{5}\right)_{2}$, that exhibits thermochromic luminescence ranging from $585 \mathrm{~nm}(8 \mathrm{~K})$ to $620 \mathrm{~nm}(300 \mathrm{~K})$, which is caused by the constraint of the pyridine substituents at lower temperatures. ${ }^{13}$ Most recently, the iodination of this cluster was reported, which described the green phosphorescence of both 7-Ianti- $\mathrm{B}_{18} \mathrm{H}_{21}$ and $4,4^{\prime}-\mathrm{I}_{2}$-anti- $\mathrm{B}_{18} \mathrm{H}_{20}$ at $525 \mathrm{~nm}$ and $545 \mathrm{~nm}$, respectively. ${ }^{12 a}$ Still, the relationship between $\mathrm{B}_{18} \mathrm{H}_{22}$ cluster structure and resulting photophysical properties has yet to be 
elucidated. It is therefore of great interest to explore functionalization methods and investigate the effect that such changes have on the photoluminescence profile. Following the first account of halogenated anti- $\mathrm{B}_{18} \mathrm{H}_{22}$, we were interested in how other halogens affect the luminescent properties of this cluster. Herein we report a synthesis for the first brominated derivative of anti- $\mathrm{B}_{18} \mathrm{H}_{22}$, 4- $\mathrm{Br}$-anti- $\mathrm{B}_{18} \mathrm{H}_{21}$, and its unique photophysical characteristics distinctively different from the other halogenated analogues.

\section{Results and Discussion}

\section{Synthesis and Structural Characterization of 4-Br-anti- $\mathrm{B}_{18} \mathrm{H}_{21}$}

Following conventional electrophilic bromination protocols used previously with other polyhedral boron clusters, ${ }^{14}$ we treated anti$\mathrm{B}_{18} \mathrm{H}_{22}$ with $\mathrm{Br}_{2}$ (1 equiv) and $\mathrm{AlCl}_{3}(10 \mathrm{~mol} \%)$ in dichloromethane under an $\mathrm{N}_{2}$ atmosphere at room temperature. Formation of the monobrominated cluster was observed after several hours, as suggested by an in situ mass spectrometry assay of the reaction mixture, although a significant amount of unreacted anti- $\mathrm{B}_{18} \mathrm{H}_{22}$ was still present after 18 hours. Increasing the amount of $\mathrm{AlCl}_{3}$ (put the mol\% here) resulted in higher conversion to $\mathrm{B}_{18} \mathrm{H}_{21} \mathrm{Br}$ with concomitant formation of the dihalogenated species, $\mathrm{B}_{18} \mathrm{H}_{20} \mathrm{Br}_{2}$. Attempts to separate these two products were successful, but resulted in poor recovered yield of $\mathrm{B}_{18} \mathrm{H}_{21} \mathrm{Br}$. Consequently, the procedure was further modified to improve the conversion to $\mathrm{B}_{18} \mathrm{H}_{21} \mathrm{Br}$, which required fewer than 1 equiv of $\mathrm{Br}_{2}$. These optimized conditions (15 mol\% $\mathrm{AlCl}_{3}$ and 0.70 equiv $\mathrm{Br}_{2}$ in $\mathrm{DCM}$ ) afforded a reaction mixture containing $\mathrm{B}_{18} \mathrm{H}_{22}, \mathrm{~B}_{18} \mathrm{H}_{20} \mathrm{Br}_{2}$, and $\mathrm{B}_{18} \mathrm{H}_{21} \mathrm{Br}$ as major products as judged by in situ mass spectrometry analysis. Subsequently, $\mathrm{B}_{18} \mathrm{H}_{21} \mathrm{Br}$ was purified from the crude mixture obtained from this reaction via high performance liquid chromatography (HPLC) using methanol/water mixture as an eluent on $\mathrm{C}-18$ modified silica stationary phase. ${ }^{15}$ While the isolated material appeared pure by ${ }^{11} \mathrm{~B}$ NMR spectroscopy, an impurity comprising ca. $5 \%$ of the bulk material was indicated by LC-MS

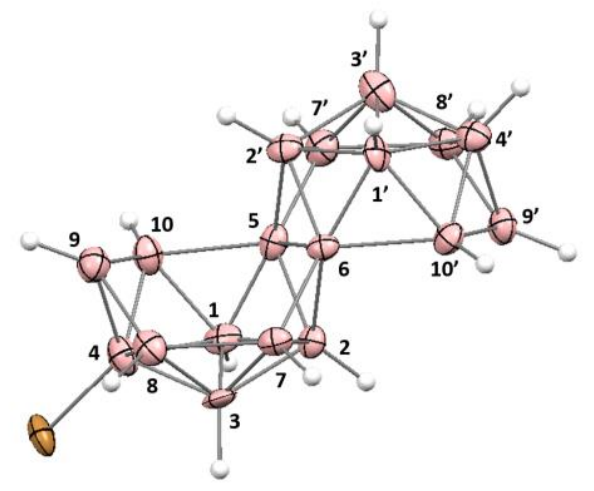

Figure 2: Single crystal X-ray structure of 4 - $\mathrm{Br}$-anti- $\mathrm{B}_{18} \mathrm{H}_{21} \bullet\left(2 \mathrm{C}_{6} \mathrm{H}_{6}\right)$ with labeled boron vertices. For clarity, the bridging hydrides, benzene solvent molecules and cocrystallized impurities are not shown. Displacement ellipsoids are drawn at a $50 \%$ probability level. analysis. Consequently, further purification via HPLC was required to obtain $>99 \%$ pure $\mathrm{B}_{18} \mathrm{H}_{21} \mathrm{Br}$ as determined by LC-MS (see Figure S6, Table S1). This product is stable when stored as a solid at $5^{\circ} \mathrm{C}$. This procedure was successfully reproduced several times to yield the same purity and photoluminescence profiles.

Single crystal $\mathrm{X}$-ray diffraction analysis was used to determine the structure of $4-\mathrm{Br}$-anti- $\mathrm{B}_{18} \mathrm{H}_{21}$. Single, $\mathrm{X}$-ray quality colorless crystals of $4-\mathrm{Br}$-anti- $\mathrm{B}_{18} \mathrm{H}_{21}$ were grown by dissolution of the compound in benzene followed by storage of the resulting solution at $5{ }^{\circ} \mathrm{C}$ (see $\mathrm{SI}$ ). The solid-state structure of $4-\mathrm{Br}$-anti- $\mathrm{B}_{18} \mathrm{H}_{21}$ (Figure 2) indicates that the boron atom connectivity in the cluster remains the same compared to the parent molecule, and that the bromine atom is located on the 4 position of the octadecaborane cage. Prior analyses of anti- $\mathrm{B}_{18} \mathrm{H}_{22}{ }^{12 a}, 16$ revealed that the 4 and $4^{\prime}$ boron vertices are the most electron rich and therefore the most likely to undergo electrophilic substitution. Indeed, the doubly iodinated cluster, synthesized with $\mathrm{I}_{2}$ and $\mathrm{AlCl}_{3}$, is substituted at the 4 and $4^{\prime}$ boron vertices. ${ }^{12 a}$ Therefore, electrophilic substitution of bromide at these locations is expected under the given experimental conditions. Even so, it is worthy to note that bromide substitution on vertices other than 4 and $4^{\prime}$ was not indicated by other analytical methods including ${ }^{11} \mathrm{~B}$ NMR spectroscopy. The selectivity of electrophilic substitution may consequently be a helpful synthetic tool in the exploration of anti- $\mathrm{B}_{18} \mathrm{H}_{22}$ chemistry.

\section{Photophysical Properties}

The absorption spectra of $4-\mathrm{Br}-a n t i-\mathrm{B}_{18} \mathrm{H}_{21}$ and anti- $\mathrm{B}_{18} \mathrm{H}_{22}$ are shown in Figure 3 . Both spectra display absorption within the ultraviolet (UV) range and the $4-\mathrm{Br}$-anti- $\mathrm{B}_{18} \mathrm{H}_{21} \mathrm{Br}$ absorbance spectrum displays minor peak changes compared to the absorption of anti- $\mathrm{B}_{18} \mathrm{H}_{22}$, shifting from $283 \mathrm{~nm}$ to $300 \mathrm{~nm}$ and $332 \mathrm{~nm}$ to 343 $\mathrm{nm}$. However, the molar absorptivity for $4-\mathrm{Br}$-anti- $\mathrm{B}_{18} \mathrm{H}_{21}\left(\varepsilon_{342}=\right.$

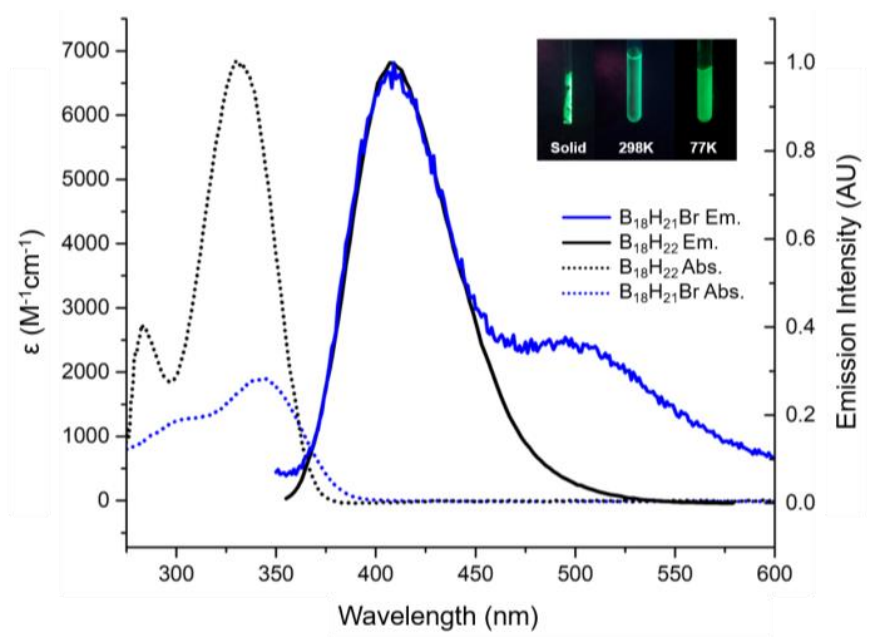

Figure 3: UV-vis spectra (dotted) of 4-Br-anti- $\mathrm{B}_{18} \mathrm{H}_{21}$ (blue, $\varepsilon_{343}=1900 \mathrm{M}^{-1} \mathrm{~cm}^{-}$ ${ }^{1}$ ) and anti- $\mathrm{B}_{18} \mathrm{H}_{22}$ (black, $\varepsilon_{332}=6800 \mathrm{M}^{-1} \mathrm{~cm}^{-1}$ ). Emission spectra (solid) of $4-\mathrm{Br}$ anti- $\mathrm{B}_{18} \mathrm{H}_{21}$ (blue) and anti- $\mathrm{B}_{18} \mathrm{H}_{22}$ (black). The wavelengths of excitation are $350 \mathrm{~nm}$ and $340 \mathrm{~nm}$, respectively. All measurements were conducted in cyclohexane solution. Inset: Luminescence of $4-\mathrm{Br}$-anti- $\mathrm{B}_{18} \mathrm{H}_{21}$ in the solid state at $298 \mathrm{~K}$ and in hexanes at $298 \mathrm{~K}$ and $77 \mathrm{~K}$. 
$\left.1900 \mathrm{M}^{-1} \mathrm{~cm}^{-1}\right)$ is significantly lower than that of anti- $\mathrm{B}_{18} \mathrm{H}_{22}\left(\varepsilon_{332}=\right.$ $\left.6800 \mathrm{M}^{-1} \mathrm{~cm}^{-1}\right)$.

Upon exposure to UV light, 4- $\mathrm{Br}$-anti- $\mathrm{B}_{18} \mathrm{H}_{21}$ exhibits luminescence that is blue-green in hexanes solution at room temperature and green when the solution is cooled to $77 \mathrm{~K}$. Likewise, this green luminescence persists in the solid state (Figure 3 , inset). While anti$\mathrm{B}_{18} \mathrm{H}_{22}$ is brightly fluorescent, we hypothesized that the bromide functionalized cluster would display some phosphorescent character due to the heavy atom effect. ${ }^{17}$ The attached bromine would presumably enhance spin-orbit coupling (SOC) and improve spin-forbidden intersystem crossing (ISC), which permits the population of triplet states that may undergo radiative decay to produce phosphorescence. To probe this possibility, photophysical data of 4- $\mathrm{Br}$-anti- $\mathrm{B}_{18} \mathrm{H}_{21}$ were first obtained under ambient conditions in cyclohexane. While the UV-vis spectra of anti- $\mathrm{B}_{18} \mathrm{H}_{22}$ $\left(\lambda_{\max } 330 \mathrm{~nm}\right)$ and anti- $\mathrm{B}_{18} \mathrm{H}_{21} \mathrm{Br}\left(\lambda_{\max } 340 \mathrm{~nm}\right)$ displayed in Figure 3 reveal slight differences in their $\lambda_{\max }$ values, the emission spectra exhibit more pronounced differences, with the brominated cluster displaying a shoulder at $503 \mathrm{~nm}$. The variability in emission color, illustrated in Figure 3 , prompted us to conduct more photoluminescence studies under various conditions. We suspected that the $503 \mathrm{~nm}$ shoulder observed could be phosphorescent in nature, but because room temperature phosphorescence is often difficult to observe the emission data were gathered at 77K. Under these conditions, bimolecular and diffusional quenching processes are minimized and molecular motions are restricted due to the molecule existing within a solid glass matrix. ${ }^{18}$ With these pathways diminished, any occurring phosphorescence is likely to be detected. Indeed, at 77K the $503 \mathrm{~nm}$ peak is intense, nearly obscuring the 410 $\mathrm{nm}$ signal (Figure 4). To investigate the possibility of oxygenquenched phosphorescence, the photophysical data in degassed $\left(\mathrm{O}_{2}\right.$-free) cyclohexane were gathered at $298 \mathrm{~K}$. The emission spectrum shows the $410 \mathrm{~nm}$ peak and a considerably more intense $503 \mathrm{~nm}$ signal (Figure 4), indicating that oxygen is at least partially responsible for the low peak intensity initially observed. The quantum yield $(\Phi)$ data, summarized in Table 1, also supports this hypothesis. Both cyclohexane solutions and PMMA films of 4-Branti- $\mathrm{B}_{18} \mathrm{H}_{21}$ possess smaller quantum yields when exposed to oxygen. The quantum yield of $4-\mathrm{Br}$-anti- $\mathrm{B}_{18} \mathrm{H}_{21}$ in cyclohexane under ambient conditions is 0.05 , which increases to 0.07 when the measurement is conducted in oxygen-free solution. These low values are surprising considering that both iodinated clusters possess QY values no less than 0.41 in oxygen-free solution. ${ }^{12 a}$ The contribution to $Q Y$ from fluorescence and phosphorescence $\left(\Phi_{\text {fluor }}\right.$ and $\left.\Phi_{\text {phos }}\right)$ was also determined (see Figures S9 and S10). Under ambient conditions in cyclohexane, both $\Phi_{\text {fluor-amb }}$ and $\Phi_{\text {phos-amb }}$ are 0.025 , while in oxygen-free solution $\Phi_{\text {fluor }}=0.024$ and $\Phi_{\text {phos }}=0.046$. Because the fluorescence quantum yield remains the same within error for both conditions, the decrease in quantum yield from 0.07 to 0.05 is most likely due to oxygen-quenched phosphorescence.
The quantum yield of a $4-\mathrm{Br}$-anti- $\mathrm{B}_{18} \mathrm{H}_{21}$ PMMA film was also assessed, increasing from $<0.01$ to 0.08 when under $N_{2}$, which is similar with the low values of the solid-state iodinated clusters $(0.06$ for 7-I-anti- $\mathrm{B}_{18} \mathrm{H}_{21}$ and 0.11 for $4,4^{\prime}-\mathrm{I}_{2}$-anti- $\left.\mathrm{B}_{18} \mathrm{H}_{20}\right) .{ }^{12 a}$ Because diffusion of oxygen at room temperature in PMMA is significantly slower than in cyclohexane, the system was allowed to equilibrate under the flow of $\mathrm{O}_{2}$ for over 30 minutes (see Figure S8). ${ }^{19}$ Finally, the fluorescent and phosphorescent nature of these peaks were further explored through lifetime $(\tau)$ decay experiments. For a cyclohexane solution of $4-\mathrm{Br}$-anti- $\mathrm{B}_{18} \mathrm{H}_{21}$, the $410 \mathrm{~nm}$ peak lifetime is $10.6 \mathrm{~ns}$ under ambient conditions (Table 1, Figure S11), compared to that of the parent borane $(11.2 \mathrm{~ns}) .{ }^{9}$ This value remains consistent under oxygen-free atmosphere ( $\tau=10.3 \mathrm{~ns})$ and decreases slightly at $77 \mathrm{~K}(\tau=9.8 \mathrm{~ns})$. The lifetime decay data was also gathered for the $503 \mathrm{~nm}$ peak, revealing a lifetime of $11.6 \mu \mathrm{s}$ in oxygen-free cyclohexane at $298 \mathrm{~K}$. At $77 \mathrm{~K}$, the lifetime is extended dramatically $(\tau=552 \mu \mathrm{s}) \quad$ (Table 1, Figure S11), which further supports the photoluminescence data in Figure 4 . The photoluminescence, quantum yield, and lifetime data for 4-Br-anti$\mathrm{B}_{18} \mathrm{H}_{21}$ under the conditions studied are summarized in Table 1 . This data can be further contextualized through a comparison to the other reported monohalogenated derivative, 7-I-anti- $\mathrm{B}_{18} \mathrm{H}_{21}{ }^{12 a}$ The iodinated cluster contains only a single emission peak that is attributed to phosphorescence, which is probably due to the increased singlet and triplet state overlap that results from the heavy iodine atom. ${ }^{12 a}$, 20 The monobrominated cluster displays attenuated ISC in comparison, achieving a balance between singlet and triplet states that permits dual fluorescent/phosphorescent emission.

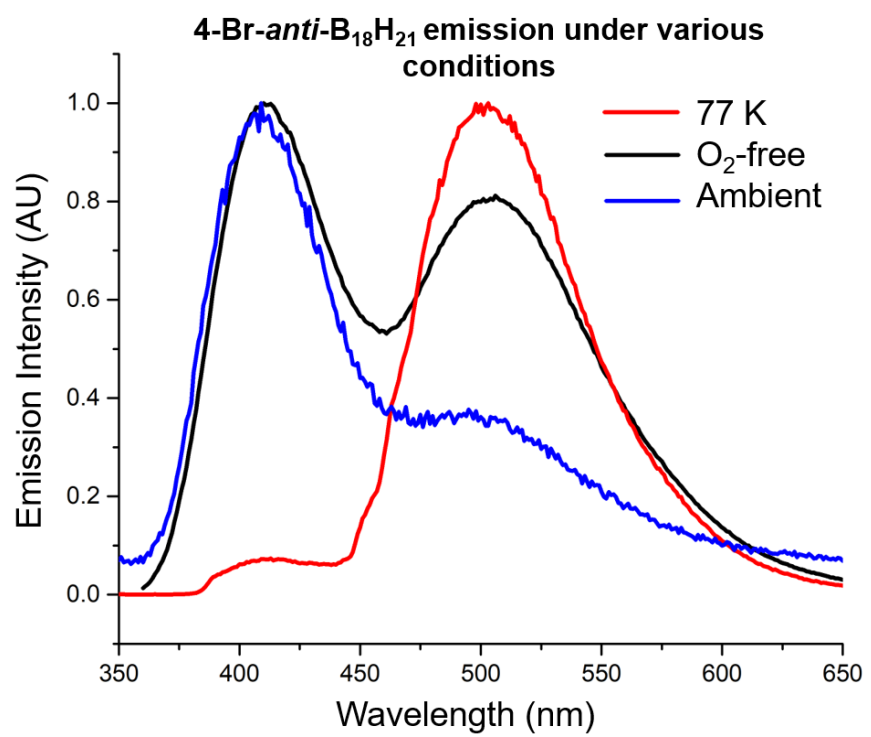

Figure 4: Emission spectra of 4- $\mathrm{Br}$-anti- $\mathrm{B}_{18} \mathrm{H}_{21}$ in cyclohexane at $298 \mathrm{~K}$ under ambient conditions (blue), at $298 \mathrm{~K}$ in $\mathrm{O}_{2}$-free cyclohexane (black), and at 77 $\mathrm{K}$ in methylcyclohexane (red). The wavelengths of excitation are $330 \mathrm{~nm}$, $350 \mathrm{~nm}$, and $340 \mathrm{~nm}$, respectively. 


\begin{tabular}{|c|c|c|c|c|c|c|}
\hline 4-Br-anti- $\mathrm{B}_{18} \mathrm{H}_{21} \mathrm{Br}$ & emission $\lambda_{\max }$ & $\phi_{\text {ambient }}$ & $\phi_{\text {O2-free }}$ & $\tau$ & $k_{r} 10^{6}\left(s^{-1}\right)$ & $k_{n r} 10^{6}\left(s^{-1}\right)$ \\
\hline $\begin{array}{l}\text { Cyclohexane } \mathrm{O}_{2^{-}} \\
\text {free }^{\mathrm{a}}\end{array}$ & $\begin{array}{l}503 \\
410\end{array}$ & - & $0.07^{a}$ & $\begin{array}{l}11.6 \mu s^{d} \\
10.3 n s^{e}\end{array}$ & $\begin{array}{c}0.0040^{g} \\
2.3^{\mathrm{h}}\end{array}$ & $\begin{array}{c}0.082^{\mathrm{g}} \\
95^{\mathrm{h}}\end{array}$ \\
\hline Cyclohexane $^{\mathrm{b}}$ & 410 & $0.05^{b}$ & - & $10.6 \mathrm{~ns}^{\mathrm{e}}$ & $2.3^{f}$ & $92^{f}$ \\
\hline Methylcyclohexane & $\begin{array}{l}503 \\
407\end{array}$ & - & - & $\begin{array}{l}552 \mu \mathrm{s}^{\mathrm{d}} \\
9.8 \mathrm{~ns}^{\mathrm{e}}\end{array}$ & $\begin{array}{l}- \\
-\end{array}$ & $\begin{array}{l}- \\
-\end{array}$ \\
\hline
\end{tabular}

Table 1 : Summary of photophysical properties of 4-Br-anti- $\mathrm{B}_{18} \mathrm{H}_{21}{ }^{\circ}$ Collected at $298 \mathrm{~K}$ under $\mathrm{N}_{2}$ atmosphere. ${ }^{\mathrm{b}} \mathrm{Collected}$ at $298 \mathrm{~K}$ under ambient conditions.

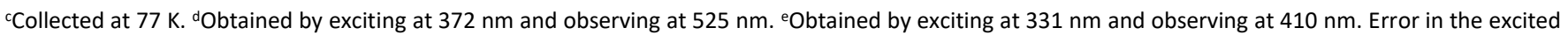
state lifetime measurement is $\pm 14 \%$ and $\pm 10 \%$, respectively. ${ }^{\mathrm{f}, \mathrm{g}, \mathrm{h}}$ Calculated according to the equations $\mathrm{k}_{\mathrm{r}}=\phi / \tau$ and $\mathrm{knr}_{\mathrm{r}}=(1-\phi) / \tau$, where $\mathrm{k}_{\mathrm{r}}$ is the radiative

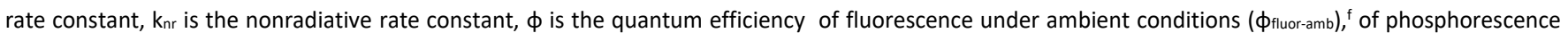
under $\mathrm{N}_{2}\left(\phi_{\text {phos }}\right)$, f fluorescence under $\mathrm{N}_{2}\left(\phi_{\text {fluor }}\right)^{\mathrm{h}}$ and $\tau$ is the excited state lifetime.

The simultaneous fluorescence and oxygen-sensitive phosphorescence demonstrated by $4-\mathrm{Br}$-anti- $\mathrm{B}_{18} \mathrm{H}_{21}$ is a property not commonly observed by small molecule metal-free emitters. ${ }^{20}$ Although dual emission was reported for thiolated anti- $\mathrm{B}_{18} \mathrm{H}_{22}$, the two luminescence bands in this molecule overlap significantly, obscuring small changes in the oxygen-sensitive phosphorescence signal. ${ }^{10}$ In contrast, the energy difference between the two emission events for $4-\mathrm{Br}$-anti- $\mathrm{B}_{18} \mathrm{H}_{21}$ is large enough that the fluctuating intensity of the phosphorescence peak is easily observed. These combined characteristics make the $4-\mathrm{Br}$-anti- $\mathrm{B}_{18} \mathrm{H}_{21}$ chromophore potentially useful for oxygen sensing. Emissive oxygen sensors have been intensely studied due to their wide applicability in biological imaging. ${ }^{21}$ Many dual-emitting sensors are nanoparticle or heavy-metal based, or require the combination of two different luminophores (one fluorescent, the other phosphorescent). ${ }^{20}$ This is due to the difficulty involved in rationally designing a single dual-emitting small molecule with the appropriate balance of populated singlet and triplet states that would give rise to dual emission. This phenomenon is especially difficult to achieve with entirely organic systems, and most dualemissive organic small molecules are based on polycyclic aromatic molecules such as pyrene ${ }^{22}$ or naphthalene. ${ }^{23}$ However, each of these methods are accompanied by a host of disadvantages, such as unequal stability between mixed dyes, weak phosphorescence, photobleaching, and bio-incompatibility. The ideal ratiometric oxygen probe exhibits intense oxygen-sensitive phosphorescence, long lifetime, resistance to photobleaching, and stability. ${ }^{20}$ To assess the applicability of $4-\mathrm{Br}$-anti- $\mathrm{B}_{18} \mathrm{H}_{21}$ as a small molecule oxygen sensor, preliminary sensing studies were conducted. Mixtures of nitrogen and oxygen gas containing varying amounts of oxygen were bubbled through a cyclohexane solution of 4-Br-anti$\mathrm{B}_{18} \mathrm{H}_{21}$ before measurements were collected (see Table S4). As shown in Figure 5, phosphorescence decreases significantly with increasing oxygen content while the fluorescence peak maintains its intensity. This system functions as a ratiometric probe through comparison of the reference signal (the oxygen-insensitive fluorescence peak) to the intensity of the oxygen-quenchable phosphorescence peak. The intermolecular, collisional quenching process by oxygen follows Stern-Volmer kinetics (see Figure 6). Using a previously reported value for the solubility of oxygen in cyclohexane ${ }^{24}$ and the Stern-Volmer relationship, the Stern-Volmer quenching constant was calculated, $\mathrm{K}_{\mathrm{sv}}=2200 \mathrm{M}^{-1}$ along with the bimolecular rate quenching constant, $k_{O 2}=1.9 \times 10^{8} \mathrm{M}^{-1} \mathrm{~s}^{-1}$. The latter value can be directly compared to the quenching rate of 7-Ianti- $\mathrm{B}_{18} \mathrm{H}_{21}\left(4.1 \times 10^{7} \mathrm{M}^{-1} \mathrm{~s}^{-1}\right)$ and 4,4'- $\mathrm{I}_{2}$-anti- $\mathrm{B}_{18} \mathrm{H}_{20}\left(6.8 \times 10^{7} \mathrm{M}^{-1} \mathrm{~s}\right.$ 1).12a It is evident that oxygen quenching occurs an order of magnitude faster in the brominated borane than its iodinated counterparts. Finally, the electrochemical properties of both anti$\mathrm{B}_{18} \mathrm{H}_{22}$ and 4-Br-anti- $\mathrm{B}_{18} \mathrm{H}_{21}$ were assessed through cyclic voltammetry (see Figure S12). While both compounds exhibit an irreversible reduction, the reduction potential shifts cathodically from $-1.36 \vee\left(\right.$ anti- $\left.\mathrm{B}_{18} \mathrm{H}_{22}\right)$ to $-1.18 \mathrm{~V}\left(4-\mathrm{Br}\right.$-anti- $\left.\mathrm{B}_{18} \mathrm{H}_{21}\right)$. This difference of $0.18 \mathrm{~V}$ indicates that the brominated cluster is a stronger oxidant than its parent borane and could be a potent

\section{Emission under varying oxygen concentrations}

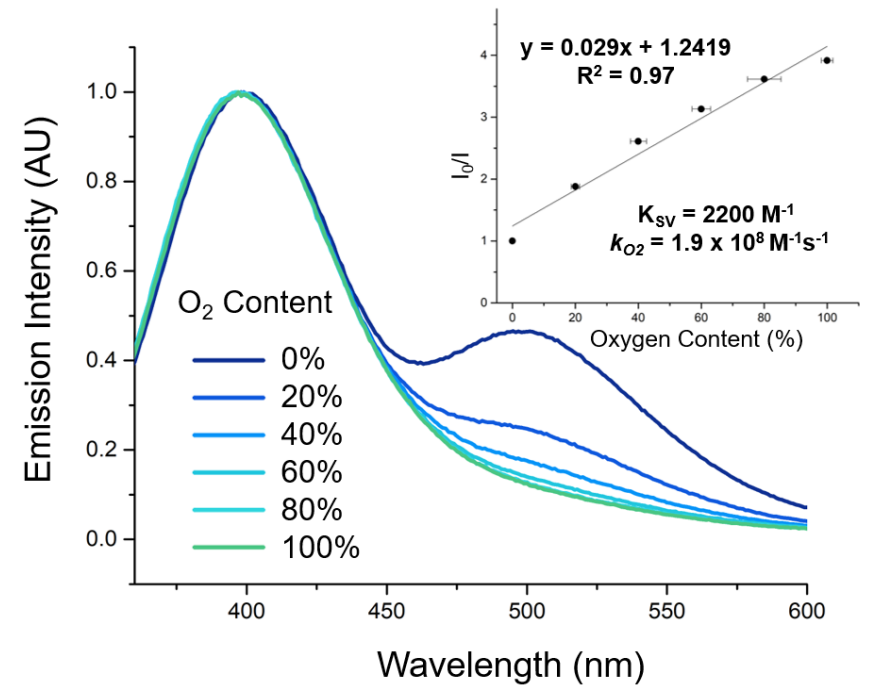

Figure 5: Emission spectra of 4-Br-anti- $\mathrm{B}_{18} \mathrm{H}_{21}$ in cyclohexane degassed with $\mathrm{N}_{2}$ and $\mathrm{O}_{2}$ gas mixtures containing varying amounts of oxygen. The wavelength of excitation was $320 \mathrm{~nm}$. Inset) Stern-Volmer plot of phosphorescence quenching of the $503 \mathrm{~nm}$ peak. The quenching constant $\mathrm{K}_{\mathrm{sv}}$ and bimolecular rate constant of $\mathrm{T}_{1}$ state quenching $k_{q}$ were calculated using 0.00116 mole fraction atm ${ }^{-1}$ as the solubility of $\mathrm{O}_{2}$ in cyclohexane ${ }^{24}$ and the Stern-Volmer equation: $I^{0} / I=1+K_{s v}\left[O_{2}\right], K_{s v}=k_{o 2} \tau_{0}$. 


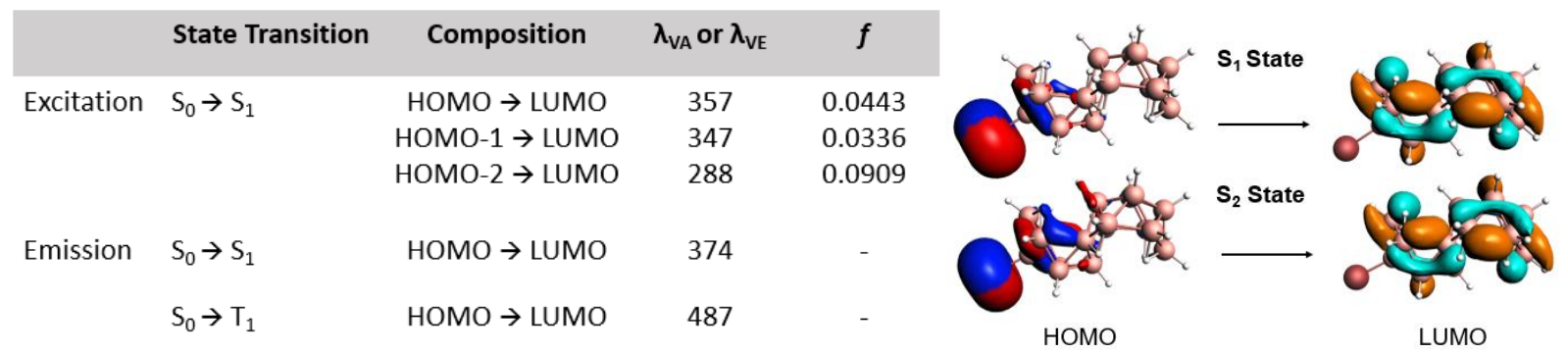

Figure 6: Left) Summary of relevant calculated absorption and emission spectra (Hybrid PBEO DZP) for 4-Br-anti-B $18 \mathrm{H}_{21}$, where $\lambda_{v A}$ is the calculated vertical absorption wavelength, $\lambda_{V E}$ is the calculated vertical emission wavelength, $f$ is the oscillator strength, and $\lambda_{\text {max }}$ is the corresponding experimental wavelength. Excitation calculations were based on the $\mathrm{S}_{0}$ optimized geometry and emission calculations were based on the $\mathrm{S}_{1}$, $\mathrm{S}_{2}$ or $\mathrm{T}_{1}$ optimized geometries. Right) Natural Transition Orbitals (NTOs) for the electronic transitions of the $S_{1}$ and $S_{2}$ states. The remaining relevant NTOs are shown in Figure S14.

photooxidant.

\section{DFT Analysis of Photophysical Data}

As a supplement to experimental data, computational calculations were conducted using TD-DFT on ADF software. A DFT hybrid PBEO functional and DZP basis set was used with scalar relativistic effects considered. Optimized geometry coordinates and frequency calculations can be found in Tables S6-9. First, the excitation spectrum was calculated based on the optimized singlet ground state geometry, $\mathrm{S}_{0}$. As shown in Figure 6, three vertical absorption $\left(\lambda_{V A}\right)$ events with oscillator strengths $>0.02$ occur between 290-350 $\mathrm{nm}$, the approximate range in which the molecule was excited in the photoluminescence experiments. While these transitions originate from the HOMO $(-8.31 \mathrm{eV})$, HOMO-1 (-8.42 eV), or HOMO$2(-9.18 \mathrm{eV})$, they are all singlet-singlet processes that excite into the LUMO (-4.09 eV). Importantly, there are two calculated bands at $347 \mathrm{~nm}$ and $357 \mathrm{~nm}$ that correspond to the broad experimental band at $343 \mathrm{~nm}$. The relatively small oscillator strengths for these transitions, which are $\sim 3-4$ times smaller than those of anti- $\mathrm{B}_{18} \mathrm{H}_{22}$ (Table S5), are in accordance with the absorption spectrum and $\varepsilon$ values in Figure 3. The emission spectrum, based on the optimized geometry of the $S_{1}$ state, was calculated, resulting in a vertical emission wavelength $\left(\lambda_{V E}\right)$ at $374 \mathrm{~nm}$, which best corresponds to the experimental $\lambda_{\max }$ at $410 \mathrm{~nm}$. In order to determine the origin of phosphorescence, the $T_{1}$ optimized geometry was calculated. The energy difference between the $S_{1}$ and $T_{1}$ states is $0.22 \mathrm{eV}, \mathrm{a}$ relatively small gap in which intersystem crossing would be possible. Therefore, phosphorescence will most likely occur from the $T_{1}$ state. The emission spectrum based on the optimized geometry of the $T_{1}$ state was calculated, giving $\lambda_{V E}=487 \mathrm{~nm}$, which can be assigned to the experimental band maximum $\lambda_{\max }=503 \mathrm{~nm}$. The natural transition orbitals (NTOs) for the $S_{1}$, and $S_{2}$ states are highlighted in Figure 7, and the $T_{1}$ NTO, which is similar to the $S_{1}$ state, is included in Figure S14. These show that the HOMO for $\mathrm{S}_{1}$ ($8.46 \mathrm{eV}), \mathrm{S}_{2}(-8.44 \mathrm{eV})$, and $\mathrm{T}_{1}(-8.68 \mathrm{eV})$ have predominantly bromine $p$-orbital $\left(n_{B r}\right)$ character. Furthermore, the p-orbital for the $S_{2}$ state is orthogonal to the $S_{1}$ and $T_{1}$ excited states, which will consequently favor SOC and therefore ISC. This is consistent with the fast ISC process and TADF observed in the experimental lifetime decay experiments. All excited states transition into the LUMO $\left(S_{1}\right.$,
$\mathrm{S}_{2}, \mathrm{~T}_{1}=-4.09,-4.20,-4.70 \mathrm{eV}$ respectively), which is distributed exclusively on the boron cluster. While the parent borane exhibits a ${ }^{1}\left(\sigma \rightarrow \sigma^{*}\right)$ transition involving B-B and B-H bonds (Figure S13), the 4$\mathrm{Br}$-anti- $\mathrm{B}_{18} \mathrm{H}_{21}$ can be characterized as ${ }^{1}\left(\mathrm{n}_{\mathrm{Br}} \rightarrow \sigma^{*}\right)$ and ${ }^{3}\left(\mathrm{n}_{\mathrm{Br}} \rightarrow \sigma^{*}\right)$ charge transfers.

\section{Conclusions}

This work presents the synthesis and photophysical characterization of the dually emissive anti- $\mathrm{B}_{18} \mathrm{H}_{21} \mathrm{Br}$ molecule, which was prepared from anti- $\mathrm{B}_{18} \mathrm{H}_{22}$ through electrophilic substitution with $\mathrm{AlCl}_{3}$ and $\mathrm{Br}_{2}$. This molecule is a rare example of a boron-based dual emitting chromophore. Its simultaneous fluorescence and phosphorescence originate from a delicate balance of $S_{1}$ and $T_{1}$ state population afforded by the bromide substituent. While the phosphorescence is quenched by oxygen, the fluorescence signal maintains its intensity, suggesting that this molecule could be useful as a ratiometric oxygen probe. More broadly, the synthesis of $4-\mathrm{Br}$-anti- $\mathrm{B}_{18} \mathrm{H}_{21}$ offers a contribution to the synthetic toolbox for anti- $\mathrm{B}_{18} \mathrm{H}_{22}$, while also elucidating the relationship between cluster structure and photophysical properties.

\section{Conflicts of interest}

There are no conflicts of interest to declare.

\section{Acknowledgements}

This work was supported by NSF Grants CHE-1846849 (NSF CAREER Award to A.M.S.) and DGE-1650604 (NSF GRFP for K.P.A.). Mr. Nicholas Bernier (UCLA) is thanked for assisting with the oxygen sensing studies. We thank Boron Specialties for a generous gift of $\mathrm{B}_{18} \mathrm{H}_{22}$.

\section{References}

1 (a) T. Kowada, H. Maeda, K. Kikuchi, Chemical Society Reviews, 2015, 44 (14), 4953. (b) A. Sutter, M. Elhabiri, G. Ulrich, Chem. Eur. J. 2018, 24, 11119.

2 (a) K. Rurack, M. Kollmannsberger, J. Daub, Angewandte Chemie International Edition, 2001, 40 (2), 385; (b) S. 
Yamaguchi, S. Akiyama, K. Tamao, JACS, 2001, 123 (46), 11372. (c) S. K. Mellerup, S. Wang, Chem. Soc. Rev. 2019, 48, 3537.

3 K. O. Kirlikovali, J. C. Axtell, A. Gonzalez, A. C. Phung, S. I. Khan, A. M. Spokoyny, Chem. Sci., 2016, 7 (8), 5132.

4 S. Yruegas, J. J. Martinez, C. D. Martin, Chem. Comm., 2018, $54(50), 6808$.

5 R. T. Kuznetsova, Y. V. Aksenova, E. N. Tel'minov, L. G. Samsonova, G. V. Maier, T. N. Kopylova, S. L. Yutanova, E. V. Antina, M. B. Berezin, G. B. Guseva, Opt. Spectrosc., 2012, $112(5), 746$.

6 (a) S. Mukherjee, P. Thilagar, Chem. Comm., 2016, 52 (6), 1070; (b) K. Kokado, Y. Tokoro, Y. Chujo, Macromolecules, 2009, 42 (8), 2925.

7 R. N. Grimes, Carboranes, 3rd ed. Academic Press: 2016.

8 (a) R. Núñez, M. Tarrés, A. Ferrer-Ugalde, F. F. de Biani, F. Teixidor, Chem. Rev., 2016, 116 (23), 14307; (b) Y. Quan, Z. Xie, Chem. Soc. Rev., 2019, 48 (13), 3660; (c) S. P. Fisher, A. W. Tomich, S. O. Lovera, J. F. Kleinsasser, J. Guo, M. J. Asay, H. M. Nelson, V. Lavallo, Chem. Rev., 2019, 119 (14), 8262.

9 M. G. S. Londesborough, D. Hnyk, J. Bould, L. SerranoAndrés, V. Sauri, J. M. Oliva, P. Kubát, T. Polívka, K. Lang, Inorg. Chem., 2012, 51 (3), 1471.

10 A. R. Pitochelli, M. F. Hawthorne, JACS, 1962, 84 (16), 3218.

11 L. Cerdán, J. Braborec, I. Garcia-Moreno, A. Costela, M. G. S. Londesborough, Nat. Commun., 2015, 6, 5958.

12 (a) M. G. S. Londesborough, J. Dolanský, J. Bould, J. Braborec, K. Kirakci, K. Lang, I. Císařová, P. Kubát, D. RocaSanjuán, A. Francés-Monerris, L. Slušná, E. Noskovičová, D. Lorenc, Inorg. Chem., 2019, 58 (15), 10248; (b) M. G. S. Londesborough, J. Dolanský, T. Jelínek, J. D. Kennedy, I. Císařová, R. D. Kennedy, D. Roca-Sanjuán, A. FrancésMonerris, K. Lang, W. Clegg, Dalton Trans., 2018, 47 (5), 1709; (c) M. G. S. Londesborough, R. Macías, J. D. Kennedy, W. Clegg, J. Bould, Inorg. Chem., 2019, 58 (19), 13258; (d) R. L. Sneath, L. J. Todd, Inorg. Chem., 1973, 12 (1), 44; (e) V. Saurí, J. M. Oliva, D. Hnyk, J. Bould, J. Braborec, M. Merchán, P. Kubát, I. Císařová, K. Lang, M. G. S. Londesborough, Inorg. Chem., 2013, 52 (16), 9266.

13 M. G. S. Londesborough, J. Dolanský, L. Cerdán, K. Lang, T. Jelínek, J. M. Oliva, D. Hnyk, D. Roca-Sanjuán, A. FrancésMonerris, J. Martinčík, M. Nikl, J. D. Kennedy, Adv. Opt. Mater., 2017, 5 (6), 1600694.

14 R. M. Dziedzic, L. M. Saleh, J. C. Axtell, J. L. Martin, S. L. Stevens, A. T. Royappa, A. L. Rheingold, A. M. Spokoyny, JACS 2016, 138 (29), 9081.

15 L. C. Sander, S. A. Wise, S. A., Anal. Chem. 1984, 56 (3), 504.

16 P. G. Simpson, W. N. Lipscomb, J. Chem. Phys., 1963, 39 (1), 26.

17 K. N. Solov'ev, E. A. Borisevich, Physics-Uspekhi 2005, 48 (3), 231.

18 N. J. Turro, V. Ramamurthy, J. C. Scaiano, Principles of molecular photochemistry : an Introduction. University Science Books: 2009.

19 (a) I. M. Krieger, G. W. Mulholland, C. S. Dickey, J. Phys. Chem., 1967, 71 (4), 1123; (b) E. I. Hormats, F. C. Unterleitner, J. Phys. Chem., 1965, 69 (11), 3677; (c) H. Y. Kaptan, J. Appl. Polym. Sci., 1999, 71 (7), 1203.

20 Y. Feng, J. Cheng, L. Zhou, X. Zhou, H. Xiang, Analyst, 2012, $137(21), 4885$

21 Y. Zhao, L. Liu, T. Luo, L. Hong, X. Peng, R. H. Austin, J. Qu, Sensor. Actuat. B-Chem., 2018, 269, 88.

22 B. J. Basu, A. Thirumurugan, A. R. Dinesh, C. Anandan, K. S. Rajam, Sensor. Actuat. B-Chem., 2005, 104 (1), 15.

23 E. D. Lee, T. C. Werner, W. R. Seitz, Anal. Chem., 1987, 59 (2), 279

24 J. D. Wild, T. Sridhar, O. E. Potter, Chem. Eng. J., 1978, 15 (3), 209 